\title{
Awakening the endogenous Leloir pathway for efficient galactose utilization by Yarrowia lipolytica
}

\author{
Zbigniew Lazar ${ }^{1,2,3^{*}}$, Heber Gamboa-Meléndez ${ }^{1,2}$, Anne-Marie Crutz- Le Coq ${ }^{1,2}$, Cécile Neuvéglise ${ }^{1,2}$
} and Jean-Marc Nicaud ${ }^{1,2}$

\begin{abstract}
Background: Production of valuable metabolites by Yarrowia lipolytica using renewable raw materials is of major interest for sustainable food and energy. Galactose is a monosaccharide found in galactomannans, hemicelluloses, gums, and pectins.

Results: Yarrowia lipolytica was found to express all the Leloir pathway genes for galactose utilization, which encode fully functional proteins. Gene organization and regulation in Y. lipolytica resembles filamentous fungi rather than Saccharomyces cerevisiae. After Y. lipolytica was grown on mixture of glucose and galactose, it was then able to metabolize galactose, including when glucose concentrations were higher than $4 \mathrm{~g} / \mathrm{L}$. However, glucose was still the preferred carbon source. Nonetheless, a strain overexpressing the four yIGAL genes of the Leloir pathway was able to efficiently use galactose as its sole carbon source. This mutant was used to produce citric acid and lipids from galactose; the yields were comparable to or greater than that obtained for the parental strain (W29) on glucose.
\end{abstract}

Conclusions: The construction of a Y. lipolytica strain able to produce citric acid and lipids from galactose is a very important step in bypassing issues related to the use of food-based substrates in industrial applications.

Keywords: Galactose, GAL genes, Citric acid, Lipid accumulation, Single-cell oil, Yeasts, Metabolic pathways

\section{Background}

Compounds such as citric acid, lipids, or sugar alcohols are of industrial interest; as a consequence, using microbes such as Yarrowia lipolytica to produce them has spurred research around the world [1-3]. From an economic and social point of view, it is very important to identify raw materials that could serve as cheap and renewable substrates and that are not already in demand for food production. Therefore, at present, research efforts are focused on using plant biomass, which contains a diversity of sugars, for the production of these valuable compounds [4]. One such sugar is D-galactose, a monosaccharide that is a C4 epimer of glucose. The polysaccharides found in plant cell walls (e.g.,

\footnotetext{
*Correspondence: zbigniew.lazar@up.wroc.pl

1 INRA, UMR1319 Micalis, 78352 Jouy-en-Josas, France

Full list of author information is available at the end of the article
}

galactomannans), gums, hemicelluloses, and pectins are rich sources of galactose [5]. Galactose also occurs naturally in milk; lactose is made up of galactose and glucose. Both milk and plant biomass are readily exploited by many microorganisms, including bacteria, yeasts, and fungi. These diverse species utilize similar pathways to break down galactose. For example, the bacterium Azotobacter vinelandii uses the non-phosphorylative DeLeyDoudoroff pathway to metabolize galactose. Galactose is oxidized, forming galactonate, which is ultimately broken down into pyruvate and glyceraldehyde 3-phosphate [6]. Another pathway, the oxido-reductive pathway, exists in filamentous fungi such as Aspergillus niger or Hypocrea jecorina; it involves a series of redox reactions that convert galactose to D-fructose [7]. However, the best-known and best-studied pathway is the Leloir pathway, which occurs in many organisms, including yeasts (e.g., Saccharomyces cerevisiae and Kluyveromyces lactis) $[8,9]$. Via 
this phosphorylative pathway, $\mathrm{D}$-galactose is converted to glucose-6-phosphate (Fig. 1a). In S. cerevisiae, $\beta$-Dgalactose is first converted to its $\alpha$-anomer by galactose mutarotase (scGAL10, YBR019C); only this anomeric form can be utilized by cells. Subsequently, $\alpha$-D-galactose is phosphorylated by galactokinase ( $s c G A L 1$, YBR020W), releasing galactose-1-phosphate. Then, galactose1-phosphate uridylyltransferase (scGAL7, YBR018C) converts this intermediate compound into UDP-galactose, simultaneously releasing glucose-1-phosphate. In the last step of the pathway, UDP-galactose is epimerized into UDP-glucose by UDP-glucose 4-epimerase (scGAL10, YBR019C). It is worth noting that, in S. cerevisiae and other Ascomycetes, the epimerase and mutarotase domains are fused together but act independently
(Fig. 1b) [10]. In addition, the mutarotase domain is not essential to galactose metabolism because the sugar anomers interconvert spontaneously in water [11]. Phosphoglucomutase converts the glucose-1-phosphate released by the pathway to glucose-6-phosphate, an intermediate compound in glycolysis. However, because phosphoglucomutase is also involved in glycogenolysis, it is not formally considered to be part of the Leloir pathway.

In the well-studied yeast $S$. cerevisiae, the structural $s c G A L$ genes (scGAL1, scGAL7, scGAL10) are clustered and subject to strong transcriptional regulation $[9,12]$. Activation of these genes occurs in the presence of galactose, but in the absence of glucose, under the action of regulatory proteins-Gal4p (activator), Gal80p (inhibitor), and Gal3p (activator and ohnolog of GAL1, which

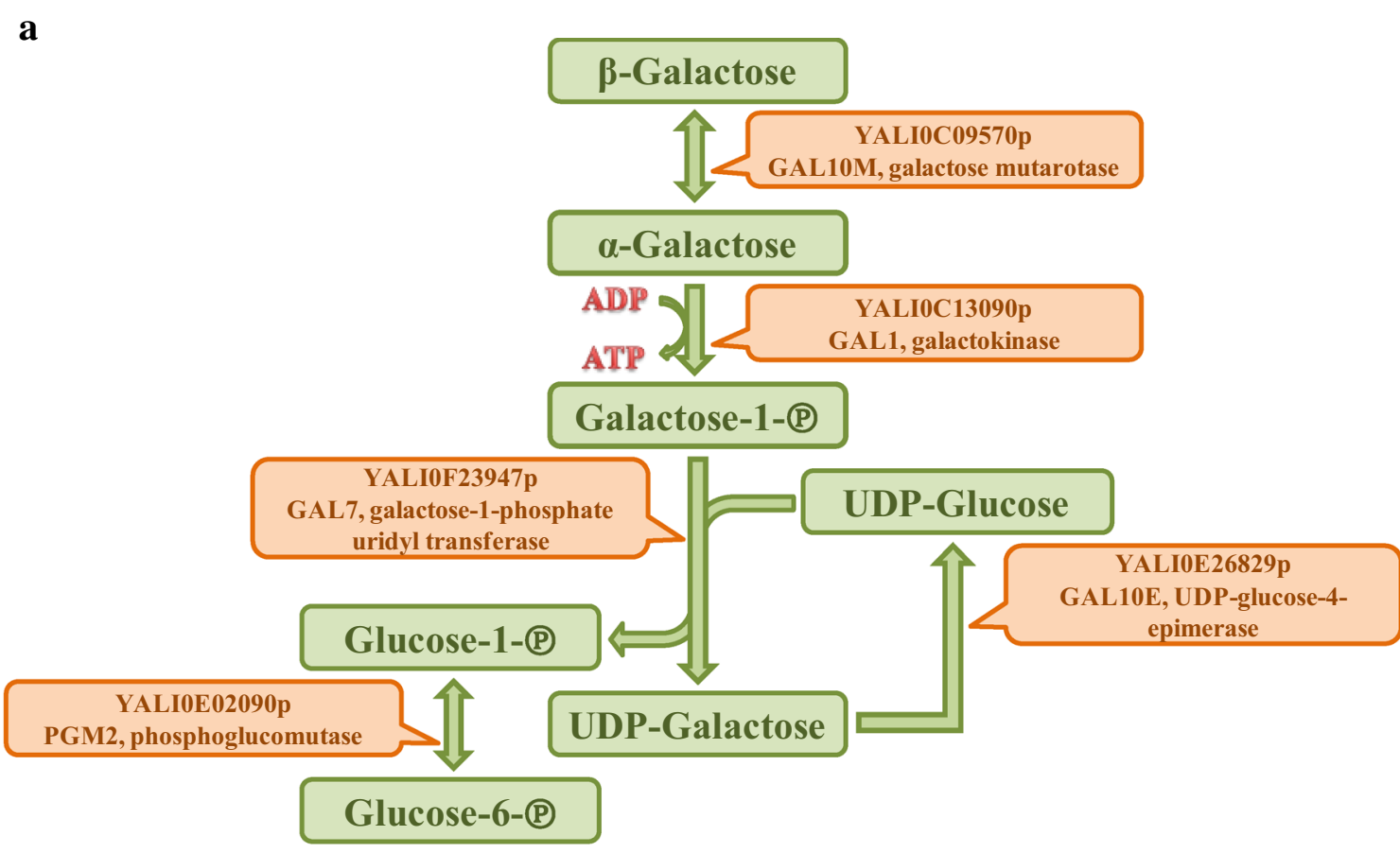

b

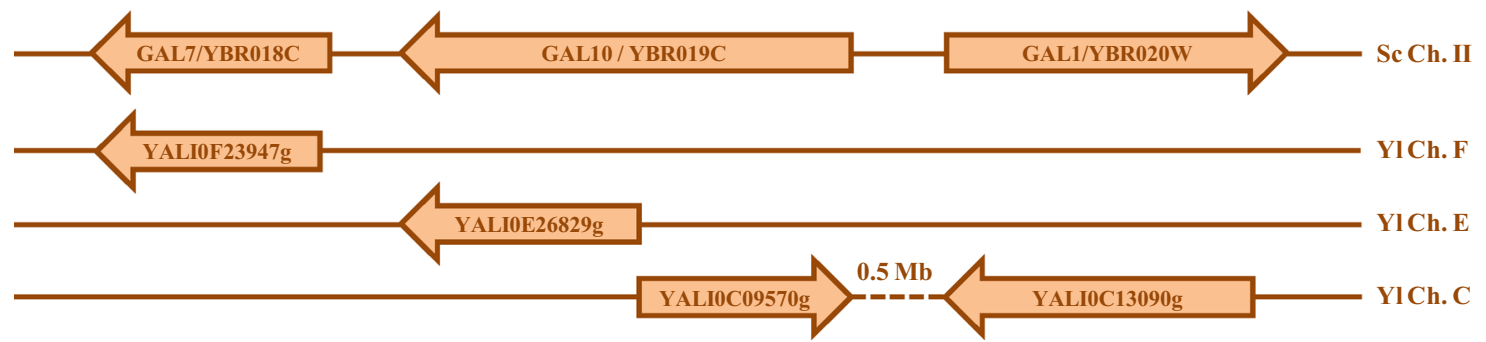

Fig. 1 Schematic representation of the Leloir pathway of galactose metabolism in Y. lipolytica (a), and GAL genes organization in the S. cerevisiae and Y. lipolytica genomes (b) 
has a regulatory function but lacks catalytic activity). On the other hand, repression of $s c G A L$ genes occurs in the presence of glucose and involves, among others, the transcriptional repressor Mig1p [13]. In addition (also in the presence of glucose), galactose uptake is inactivated through degradation of the galactose transporter Gal2p [14]. Unlike S. cerevisiae, the Gal3p does not exist in the yeast $K$. lactis, while Gal1p is responsible for both enzymatic and regulatory activities [8]. Furthermore, in the latter yeast, $G A L$ genes were shown to be semiconstitutively expressed at low levels and induced during the stationary phase [15].

In filamentous fungi, the Leloir genes are not clustered as they are in S. cerevisiae and K. lactis [10]. Moreover, in $H$. jecorina, A. niger, and Aspergillus nidulans, they exhibited a high basal expression levels on various carbon sources such as glucose, arabinose, xylose, lactose, cellobiose, or glycerol [5, 16-21]. This finding indicates that important differences exist in galactose metabolism regulation in filamentous fungi versus in $S$. cerevisiae. The first and the most significant difference is the presence of at least two different pathways in the genomes of filamentous fungi [7, 17, 18]. Another difference is that proteins that regulate galactose utilization in $S$. cerevisiae-such as Gal4p-are not found in their genomes [16]. However, other proteins regulating galactose metabolism are found in A. nidulans (GalR and GalX) [5] and other aspergilli (GalX) [5]. In addition, glucose does not cause carbon catabolite repression of the GAL pathway in filamentous fungi [16, 17]. All these data indicate that the regulation of the Leloir pathway (or its mechanism) described in $S$. cerevisiae is not conserved in other Ascomycetes [16].

Yarrowia lipolytica is a dimorphic yeast that belongs to the subphylum Saccharomycotina. Its genome contains all the Leloir genes (Fig. 1a), scattered on different chromosomes as in $H$. jecorina (Fig. 1b) [10]. In addition, the UDP-glucose-4-epimerase and galactose mutarotase are encoded by two different genes in both $Y$. lipolytica and $H$. jecorina $[10,17,18]$. However, the $Y$. lipolytica species is unable to use galactose as its sole carbon source. Therefore, the objective of this study was to figure out whether these genes are even expressed and whether they encode fully functional proteins. The goal was also to determine the culture conditions under which $Y$. lipolytica cells use galactose as a carbon source. Above all, the aim was to construct a $Y$. lipolytica strain that could utilize galactose efficiently and be used for different biotechnological applications. For instance, galactose-containing raw materials, such as polysaccharides obtained from plant cell walls (i.e., hemicelluloses), could eventually supplant food-based substrates in industrial applications.

\section{Results and discussion}

The yeast $Y$. lipolytica is able to use a few monosaccharides as carbon sources, namely glucose, fructose, and mannose [22]. However, in contrast to S. cerevisiae, none of the $Y$. lipolytica WT strains are able to utilize pure galactose.

\section{Structural and regulatory genes for the Leloir pathway in Yarrowia lipolytica}

The conservation of the Leloir pathway proteins was examined. The proposed nomenclature of the $y l G A L$ genes will be used in this paper as follows: $y l G A L 1$ (YALI0C13090g, galactokinase), $y l G A L 7$ (YALIOF23947g, galactose-1-phosphate uridyl transferase), ylGAL1OE (YALIOE26829g, UDP-glucose-4 Epimerase), and $y l G A L 10 M$ (YALI0C09570g, galactose Mutarotase). In $Y$. lipolytica, UDP-glucose-4 epimerase ( $y l G A L 10 E)$ is the most conserved of the GAL proteins also found in $S$. cerevisiae and $H$. jecorina (69-76 \% amino-acid similarity), whereas galactose mutarotase $(y l G A L 10 \mathrm{M})$ is the least conserved (36-42\% similar) (Table 1; http://blast. ncbi.nlm.nih.gov/Blast.cgi). Although the structural genes necessary for galactose utilization are present in $Y$. lipolytica, the genes encoding regulatory proteins in $S$. cerevisiae (i.e., scGAL3, scGAL4, and scGAL80) were not found. Furthermore, GAL4-binding sites are not present in the promoter regions of $y l G A L$ genes (data not shown), which is also the case for $H$. jecorina [18]. Despite this fact, $H$. jecorina is able to grow well on galactose. Past work has shown that the fission yeast Schizosaccharomyces pombe also contains all of the Leloir genes but fails to grow when galactose is the sole available carbon source [23]. The MIG1 gene (YALIOE07942g), which homolog represses expression of GAL genes in $S$. cerevisiae, has been identified in Y. lipolytica [24]. Disruption of $y l M I G 1$ did not result in growth of $Y$. lipolytica on galactose (data not shown).

\section{Yarrowia lipolytica GAL genes are expressed}

To examine $y l G A L$ gene expression, $Y$. lipolytica was grown in $1.0 \%$ glucose medium followed by its transfer to a suite of media containing two different concentrations $(0.1$ and $1.0 \%)$ of three different monosaccharides (galactose, glucose, and mannose), and transcription analyses were performed (Fig. 2a; for details see "Methods"). Galactose was the target compound, glucose was a potential repressor, and mannose was a neutral sugar in catabolite repression. The three main $y l G A L$ genes $(y l G A L 1, y l G A L 7, y l G A L 10 E)$ were expressed under all the conditions, but $y l G A L 10 M$, the least important gene in galactose utilization, showed very weak expression (Fig. 2a). This pattern is similar to that observed in $H$. jecorina $[17,19]$. Because the $y l G A L$ genes were 


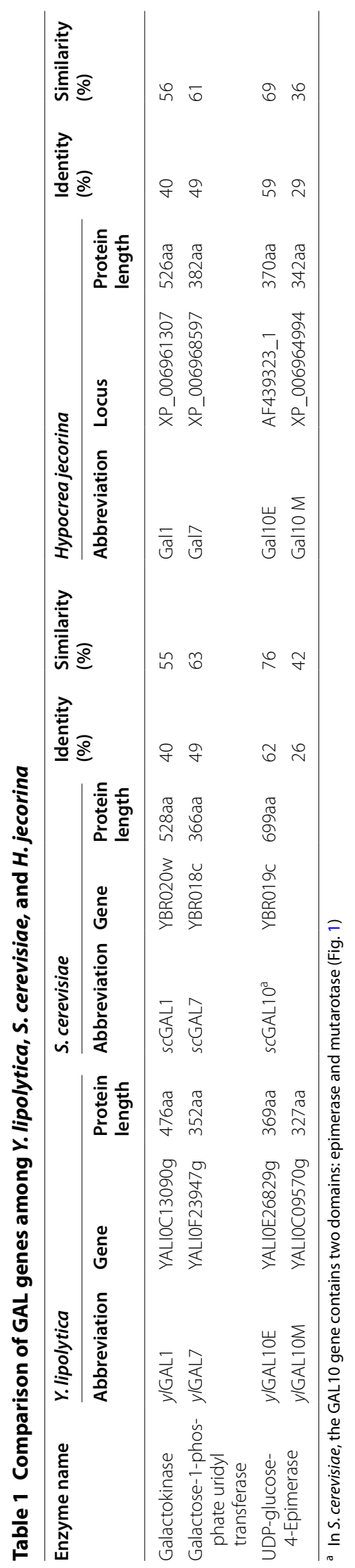



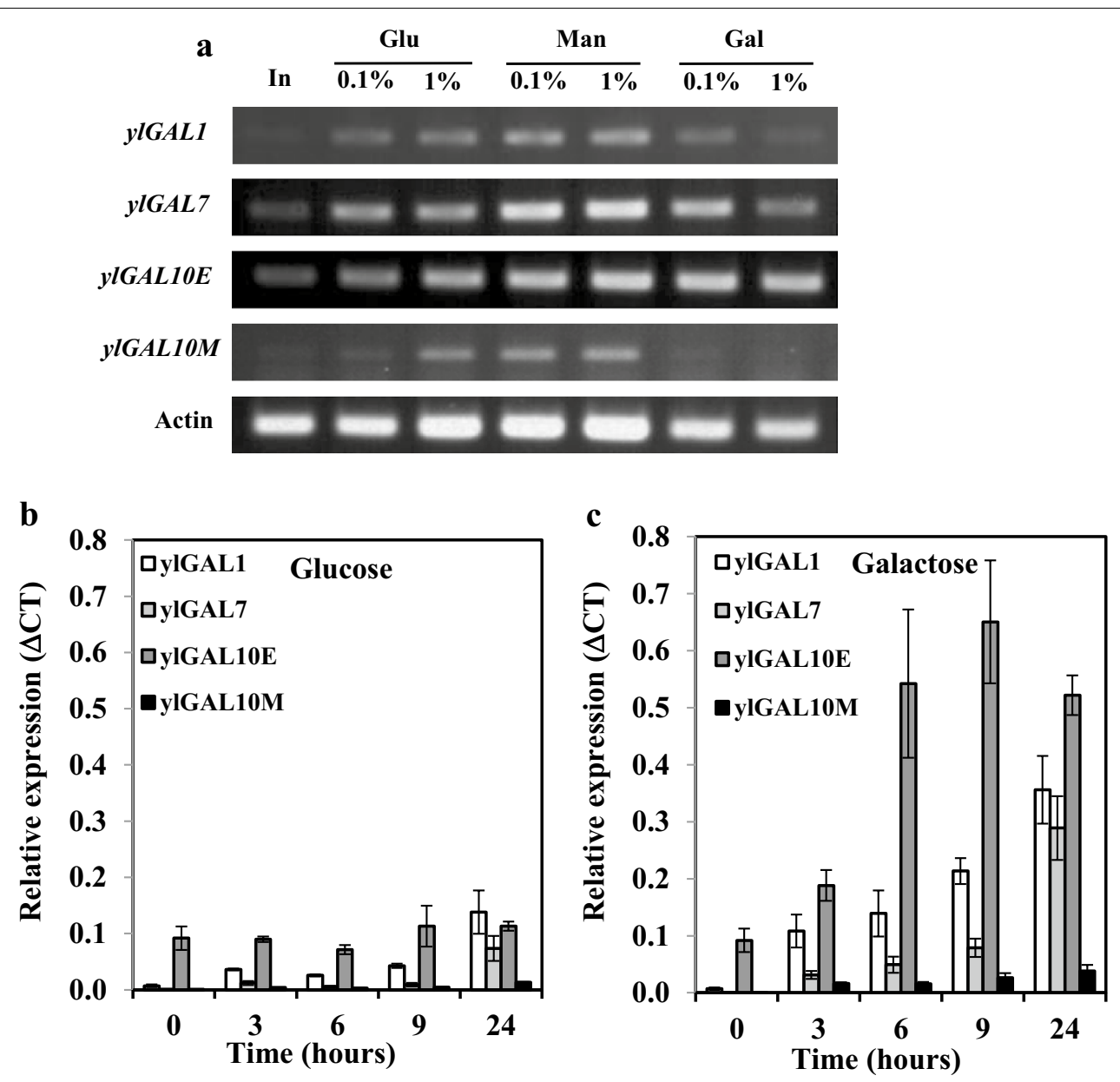

d

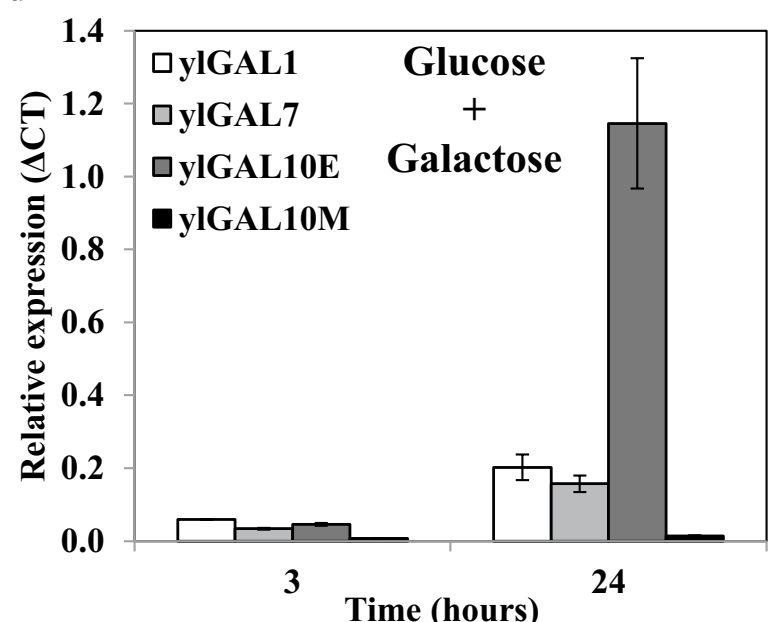

Fig. 2 Expression profiles of y/GAL genes in Y. lipolytica W29. Cells were first growing for $16 \mathrm{~h}$ in YNB medium with $1.0 \%$ of glucose and then incubated for 3-24 $\mathrm{h}$ in YNB medium containing the indicated sugar at 0.1 or $1.0 \%$. End-point RT-PCR was performed after $3 \mathrm{~h}$ incubation in glucose, mannose, or galactose (a). Kinetics of ylGAL genes expression was monitored by quantitative RT-PCR in Y. lipolytica W29 incubated in YNB medium containing $1.0 \%$ glucose $(\mathbf{b}), 1.0 \%$ galactose $(\mathbf{c})$, or a mixture of $1.0 \%$ glucose and $1.0 \%$ galactose $(\mathbf{d})$. Gene expression levels were normalized based on the expression levels of the actin gene $\left(\Delta C_{T}\right)$. In inoculum 
expressed when $Y$. lipolytica was grown on glucose, it appears that they are not subject to catabolic repression as they are in $S$. cerevisiae [12, 13]. A similar pattern was observed in $A$. niger, which shows poor growth on galactose, even though all of its Leloir orthologs are expressed on all the carbon sources studied [20].

Since the $y l G A L$ genes were not repressed by glucose, a kinetics analysis of their quantitative expression on glucose, galactose and mixture of both was conducted (Fig. 2b-d). The gene profiles show that, on glucose, expression of the UDP-glucose-4-epimerase gene $(y l G A L 10 E)$ was constant, whereas expression of galactokinase $(y l G A L 1)$ and galactose-1-phosphate uridyl transferase $(y l G A L 7)$ genes increased after $24 \mathrm{~h}$ (Fig. 2b). Once again, the galactose mutarotase gene ( $y l G A L 10 M)$ had the lowest expression levels. On galactose, there was a slight increase in expression of $y l G A L$ genes $(y l G A L 1$, $y l G A L 7, y l G A L 10 E)$ over time: it reached between 2.7 and 4.6 after $24 \mathrm{~h}$ (Fig. 2c). Therefore, the $y l G A L$ genes were upregulated in the presence of galactose. The expression of $y l G A L$ genes in the mixture of $1.0 \%$ glucose and $1.0 \%$ galactose (Fig. $2 \mathrm{~d}$ ) resembled the expression profile of these genes on $1.0 \%$ glucose (Fig. 2b), except for $y l G A L 10 E$ gene which was more than 10 times upregulated by the presence of galactose in the medium (Fig. 2d). This result indicates that in Y. lipolytica, the $y l G A L$ genes are not subject of glucose catabolite repression since $y l G A L 10 E$ can be upregulated by galactose also in the presence of glucose. In $A$. nidulans and $H$. jecorina, galD (GAL7) and galE (GAL1) have also been reported to be upregulated in the presence of galactose versus glucose $[17,19,21]$. However, in contrast to $y l G A L 10 E$ gene, which is also upregulated by galactose, the expression of its homolog GAL10 of $H$. jecorina is not improved by this sugar $[16,18]$.

\section{Yarrowia lipolytica GAL genes are functional}

To investigate the activity of the proteins encoded by the $Y$. lipolytica GAL genes, a functional complementation test was performed using $S$. cerevisiae. The $y l G A L$ genes were amplified and cloned into a multicopy pRS426 vector under the control of the scTEF promoter. The $S$. cerevisiae transformants obtained were subsequently tested to determine if they could grow when galactose was the sole carbon source (Fig. 3). The three cloned $y l G A L$ genes, $y l G A L 1, y l G A L 7$, and $y l G A L 10 E$, complemented their corresponding $S$. cerevisiae GAL-deletion mutants and restored growth on galactose. This result shows that the $y l G A L$ genes encode functional Leloir proteins. The fact that the $S$. cerevisiae mutant (depleted for both epimerase and mutarotase functions) expressing only the $y l G A L 10 E$ gene demonstrated growth, while the mutant expressing the $y l G A L 10 M$ gene did not confirm what Seiboth et al. [18] found: that the epimerase, not the mutarotase, activity of $s c G A L 10$ is required for $S$. cerevisiae to be able to use galactose as a sole carbon source [11]. Because $K$. lactis galactokinase demonstrates two activities - it acts as an enzyme and a regulatory protein [8]-the putative regulatory function of $Y$. lipolytica galactokinase was also examined. The $y l G A L 1 p$ gene, which complemented the $S$. cerevisiae $\triangle$ GAL1 mutant, was not able to restore normal growth on galactose for the $S$. cerevisiae $\triangle$ GAL3 mutant (Fig. 3), in contrast to its $K$. lactis counterpart [8]. ScGAL3, which is an ohnolog of $s c G A L 1$, diverged after a whole genome duplication event, losing the ancestral gene's enzymatic activity but retaining its regulatory function. This finding suggests that $y l G A L 1$ does not share $s c G A L 3$ 's regulatory role; this function was either lost in $Y$. lipolytica over the course of evolution, or acquired later in hemiascomycetes (perhaps at the base of the Saccharomycetaceae branch).

\section{Validation of Leloir pathway functionality in Yarrowia lipolytica}

Given the evidence that the Leloir pathway was potentially functional in $Y$. lipolytica, galactose utilization by the species was investigated (Fig. 4). The $y l G A L$ genes were expressed when the yeast was grown on glucose, but galactose alone did not allow growth. As a result, growth and sugar consumption by Y. lipolytica W29 (the wild-type strain) in YNB medium containing a mixture of glucose and galactose (0.1 or $1.0 \%)$ were analyzed. First, a control experiment was conducted in which growth and sugar consumption on glucose versus galactose were examined. As expected, when galactose was the sole carbon source, it was not consumed, whereas 0.1 and $1.0 \%$ glucose were depleted within 12 and $32 \mathrm{~h}$, respectively (Fig. 4a, c). Surprisingly, when the same strain was grown in medium containing both $0.1 \%$ glucose and $0.1 \%$ galactose, it was able to use both sugars (Fig. $4 \mathrm{~b}$ ). The specific glucose utilization rate was the same as for the glucose-only culture $(0.60 \pm 0.04 \mathrm{~g} / \mathrm{g} / \mathrm{h})$. In contrast, the specific galactose utilization rate reached ten times lower value than the one for glucose $(0.060 \pm 0.005 \mathrm{~g} / \mathrm{g} / \mathrm{h})$ and remained constant through the process. In addition, sugar consumption was also tested using cultures containing higher concentrations of both monosaccharides ( $1 \%)$ to eliminate the influence of any putative sugar sensors, which could change carbon metabolism (Fig. 4d). As in the previous experiment, Y. lipolytica W29 used both glucose and galactose from the beginning, but the glucose consumption rate was much higher than the galactose consumption rate $(0.15 \pm 0.01 \mathrm{~g} / \mathrm{g} / \mathrm{h}$ versus $0.030 \pm 0.003 \mathrm{~g} / \mathrm{g} / \mathrm{h}$, respectively). It is worth noting that, not only was galactose consumed by the cells, but it was also partially used for biomass production (Fig. 4b, d). In 


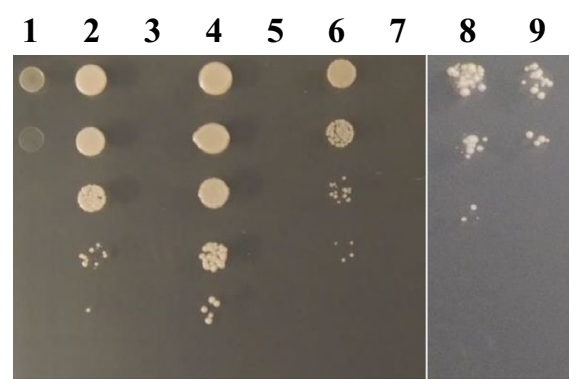

1. $\triangle \mathrm{GAL} 1-\mathrm{EV}$

2. $\triangle$ GAL1-ylGAL1

3. $\triangle \mathrm{GAL} 7-\mathrm{EV}$

4. $\triangle$ GAL7-ylGAL 7

5. $\triangle \mathrm{GAL} 10-\mathrm{EV}$

6. $\triangle$ GAL10-ylGAL10E

7. $\triangle$ GAL10-ylGAL10M
8. $\triangle$ GAL3-EV

9. $\triangle$ GAL3-ylGAL1

Fig. 3 Complementation of GAL gene deletion in S. cerevisiae using GAL homologs found in Y. lipolytica. EV—strains complemented for uracil deletion using a pRS426TEF empty vector
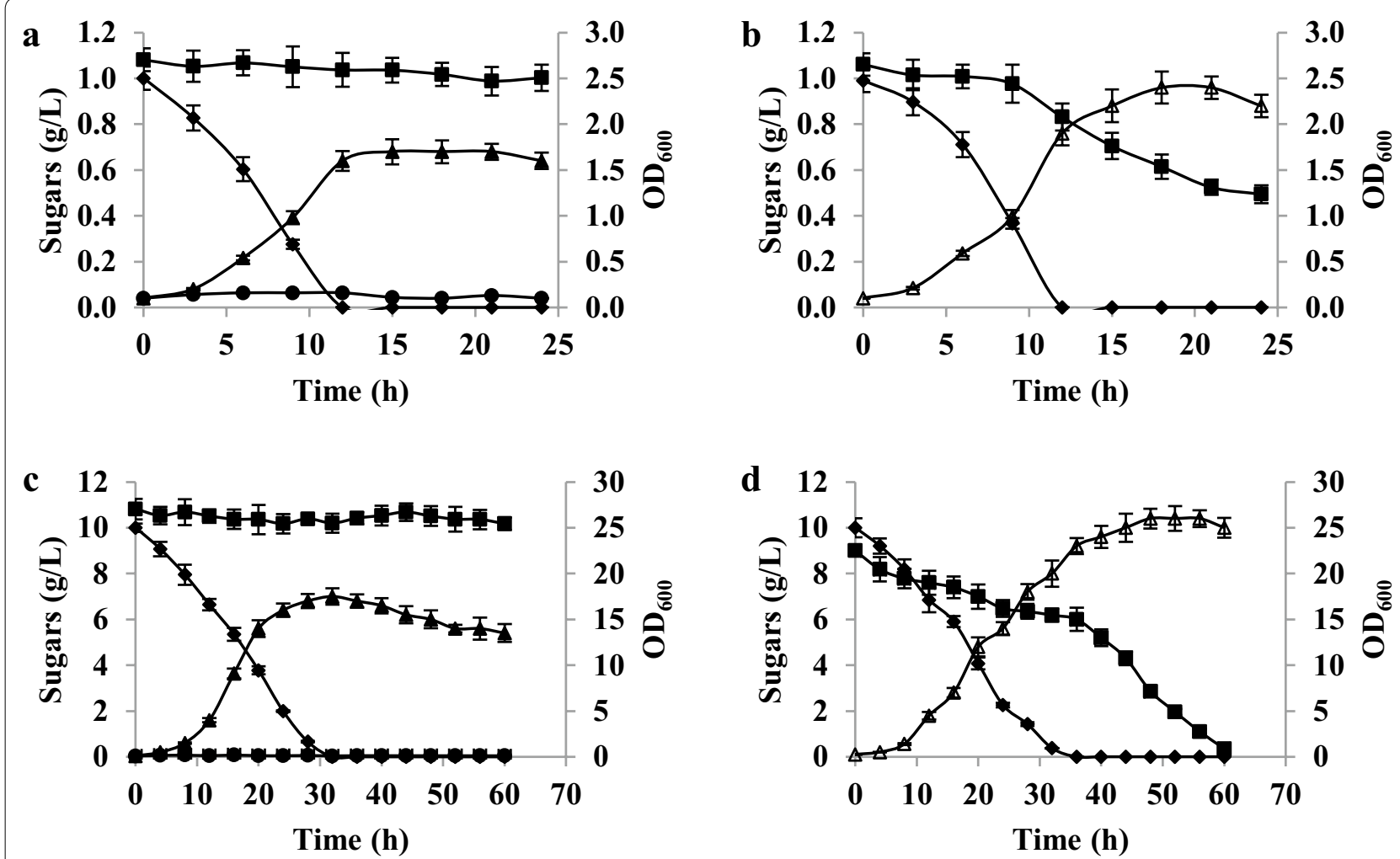

Fig. 4 Changes in concentration of sugars and growth during cultures of Y. lipolytica W29 in YNB medium with glucose and galactose. a YNB medium with single $0.1 \%$ glucose or $0.1 \%$ galactose, $\mathbf{b}$ YNB medium with mixture of $0.1 \%$ glucose and $0.1 \%$ galactose, c YNB medium with single $1 \%$ glucose or $1 \%$ galactose, d YNB medium with mixture of $1 \%$ glucose and $1 \%$ galactose. Glucose (filled diamond), galactose (filled square), optical density of cells growing in cultures with-glucose (filled triangle), galactose (filled circle), mixture of glucose and galactose (unfilled triangle)

addition, deletion of $y l G A L 10 E$ gene resulted in dramatic decrease of galactose consumption (Additional file 1), stating the involvement of the Leloir pathway in galactose utilization.

The next step was therefore to determine the concentration of glucose that $Y$. lipolytica requires to be able to use galactose. $Y$. lipolytica W29 was therefore grown in a suite of media containing $1.0 \%$ galactose and a range of glucose, from 0.1 to $1.0 \%$. At a glucose concentration of $0.1 \%$, growth was very weak and galactose was not consumed (Fig. 5a). At higher glucose concentrations (0.2-0.4\%), a small amount of galactose was also utilized; however, after the glucose was used up, galactose consumption stopped (Fig. 5b, c). At even higher glucose concentrations, $Y$. lipolytica consumed galactose more efficiently, following a short delay (Fig. 5d-f). Galactose consumption increased once the glucose had been drained from the medium, which is also when the cells 

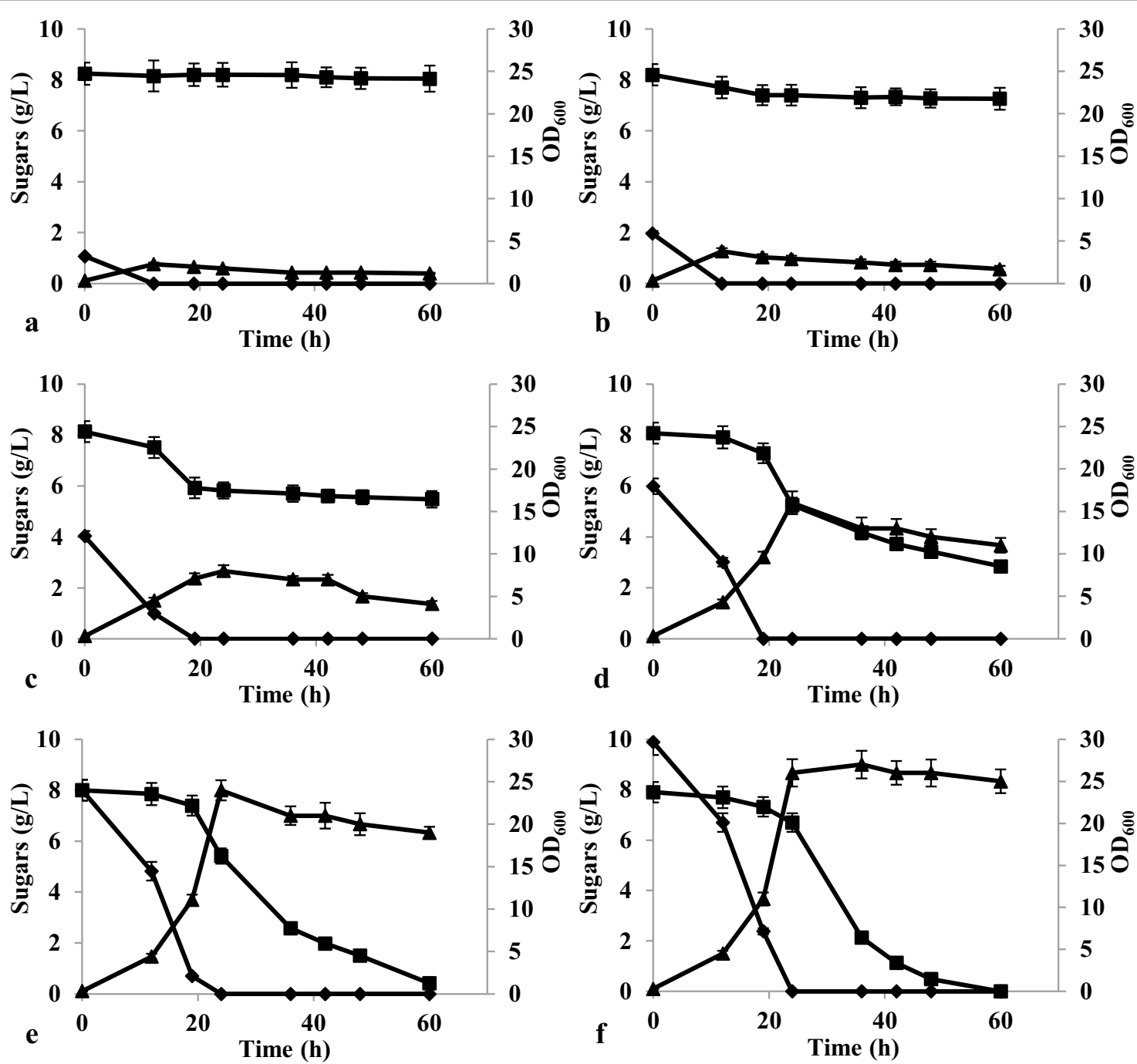

Fig. 5 Comparison of growth and sugar utilization of $Y$. lipolytica W29 in YNB medium with $1 \%$ galactose and different concentration of glucose: $0.1 \%(\mathbf{a}) ; 0.2 \%(\mathbf{b}) ; 0.4 \%(\mathbf{c}) ; 0.6 \%$ (d); $0.8 \%$ (e); $1.0 \%$ (f). Glucose (filled diamond), galactose (filled square), $\mathrm{OD}_{600}$ (filled triangle)

enter into the stationary phase (Fig. $5 \mathrm{~d}-\mathrm{f}$ ). The fact that $Y$. lipolytica needs glucose concentrations to be higher than $0.4 \%$ to efficiently use galactose suggests that it first requires access to a metabolically favorable carbon source that promotes growth and viability before it can use galactose. This phenomenon could result because Y. lipolytica is strictly aerobic, and the large amount of energy required to synthesize Leloir proteins cannot be acquired when the yeast begins its growth on galactose. In S. cerevisiae exposed to oxygen-limited conditions, when the yeast is switched from glucose to galactose, energy levels rapidly drop, and Leloir proteins are not synthesized in sufficient quantities to make galactose utilization possible [25]. However, this explanation for the observed Y. lipolytica phenotype must be investigated further.
Overexpression of all Yarrowia lipolytica GAL genes induces efficient growth on galactose

Because Y. lipolytica's GAL genes were found to be functional, the goal became to see if it was possible to improve the Leloir pathway such that $Y$. lipolytica could efficiently use galactose as a sole carbon source. All the $y l G A L$ genes were placed under the control of the strong constitutive TEF promoter and introduced individually or in various combinations into the Y. lipolytica PO1d background. The resulting strains were then tested to see if they could grow on galactose alone. When the transformants were grown on glucose, they showed normal growth and no morphological changes, suggesting that their physiology was not affected (Fig. 6a). Only mutants in which $y l G A L 1, y l G A L 7$, and $y l G A L 10 E$ 
$\mathbf{a}$

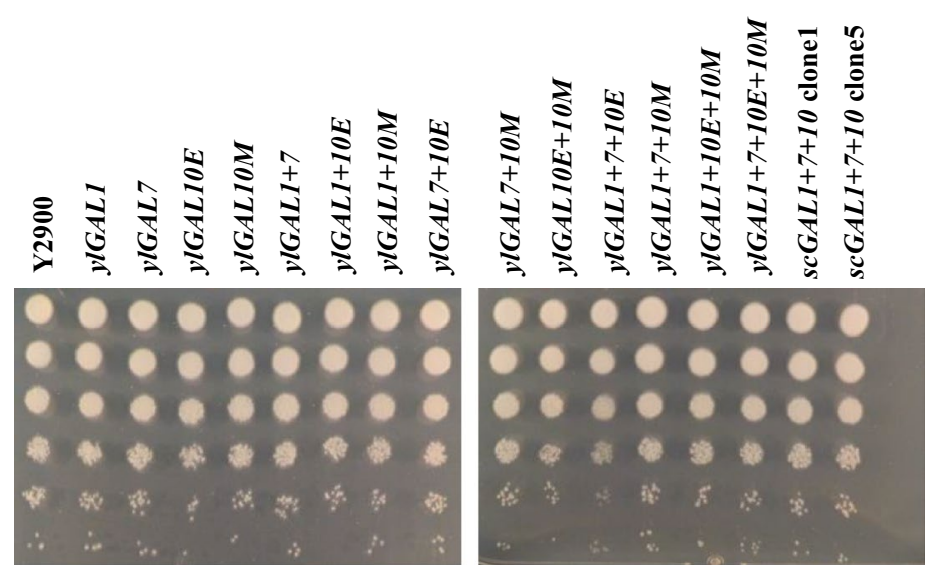

Gal $0.1 \%$
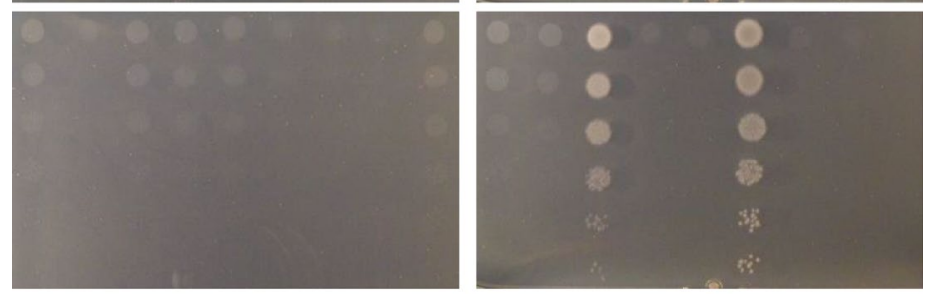

Gal $1.0 \%$
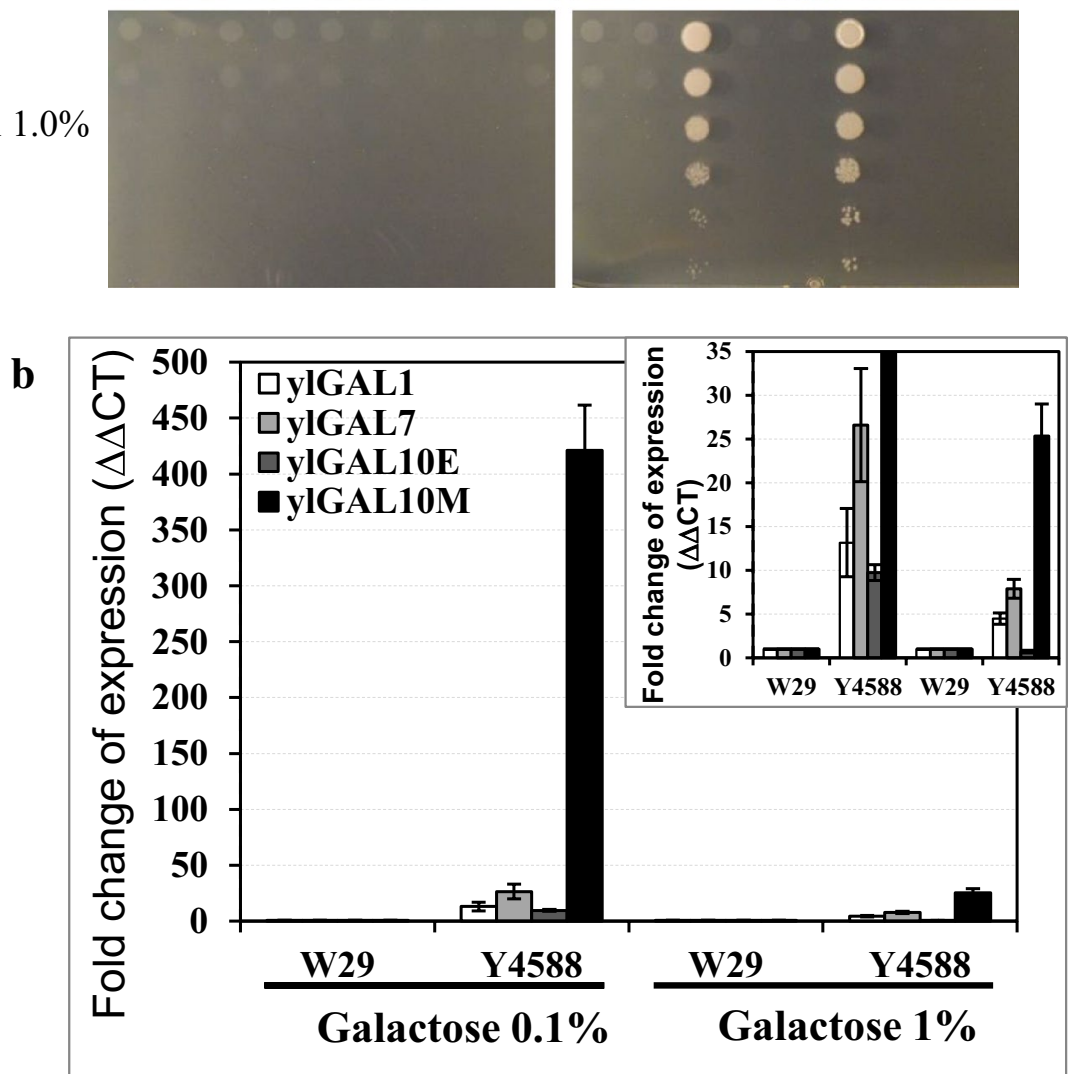

Fig. 6 Functional analysis of Leloir pathway overexpression in Y. lipolytica and fold change in the expression of the $y / G A L$ genes. Growth of different Y. lipolytica transformants overexpressing y/GAL and scGAL genes on plates of YNB medium containing glucose or galactose-incubation at $28^{\circ} \mathrm{C}$, $48 \mathrm{~h}$ (a). Fold changes in the expression of $y / G A L$ genes in the quadruple mutant, Y4588 (in which all the Leloir genes were overexpressed), relative to Y. lipolytica W29 (the wild-type strain) (b); yeast were incubated for $3 \mathrm{~h}$ in YNB medium containing 0.1 or $1.0 \%$ galactose. Gene expression levels were normalized based on the expression of the actin gene 
were simultaneously overexpressed could grow within $48 \mathrm{~h}$ on both, 0.1 and $1.0 \%$ galactose (Fig. 6a, line 12). Mutarotase activity, which is not required for galactose metabolism, nonetheless appeared to slightly improve galactose utilization (Fig. 6a, line 15). Interestingly, the overexpression of all the $S$. cerevisiae Leloir genes in $Y$. lipolytica was not efficient and resulted in weak, delayed growth (Additional file 2A). Additional analysis of growth patterns showed that the $Y$. lipolytica transformants overexpressing the $y l G A L$ genes, with the exception of Y4585 and Y4588, took a long time to grow on galactose. The Y4577 strain, in which $y l G A L 1$ and $y l G A L 7$ were overexpressed, showed visible growth after 2 weeks of incubation but revealed normal morphology on plates (Additional file 2B). This fact supports the observation, that the native $y l G A L 1 O E$ expression is higher than that of the rest of the $y l G A L$ genes, but needs time for it to reach an efficient level. In addition, the Y4578 strain, in which $y l G A L 1$ and $y l G A L 10 E$ were overexpressed, also showed visible growth after 2 weeks of incubation, albeit much less efficient than Y4577 (Additional file 2B). This finding underscores that $y l G A L 7$ expression results in functional protein biosynthesis but not normal levels for galactose utilization in the whole cell population.

The strong increase in gene expression in the quadruple mutant (Y4588) showed that, when galactose concentrations were low, each gene was overexpressed compared to the parental strain; for instance, expression was 400 times higher for $y l G A L 10 M$ (Fig. 6b). Surprisingly, when galactose concentrations were high $(1.0 \%)$, the change in gene expression levels was not so sharp, especially in the case of $y l G A L 10 E$. The parental strain expresses $y l G A L 10 E$ at high levels when grown in $1.0 \%$ galactose, which could explain why the overexpression of this particular gene did not increase transcript levels (Fig. 6b). Overexpressing all four of the $y l G A L$ genes efficiently activated the Leloir pathway and created a strain that can use galactose as its sole carbon source.

\section{Sugar utilization kinetics and transporters' expression in Yarrowia lipolytica overexpressing yIGAL genes}

Glucose must be present in the culture medium for the Y. lipolytica wild-type (W29) strain to be able to utilize galactose. Overexpression of all the genes in the Leloir pathway allowed $Y$. lipolytica cells to grow on media whose sole carbon source was galactose. The next step was to determine if glucose had an effect on galactose utilization in the Y. lipolytica quadruple mutant (Y4588). To this end, its growth and sugar utilization in $1 \%$ glucose, $1 \%$ galactose, and a mixture of $1 \%$ glucose and $1 \%$ galactose were characterized. The kinetics of sugar consumption were the same when the strain was grown in the single sugar cultures, reaching a specific consumption rate of $0.13-14 \pm 0.01 \mathrm{~g} / \mathrm{g} / \mathrm{h}$; slightly more biomass was produced when the strain was grown on glucose alone (Fig. 7a). However, sugar utilization dynamics changed in the mixed medium (Fig. 7b). During the exponential growth phase, the specific glucose and galactose utilization rates were $0.13 \pm 0.01$ and $0.040 \pm 0.003 \mathrm{~g} / \mathrm{g} / \mathrm{h}$, respectively, while during the stationary phase, both values decreased to $0.020 \pm 0.001$ and $0.030 \pm 0.003 \mathrm{~g} / \mathrm{g} / \mathrm{h}$ for glucose and galactose, respectively. This same pattern was also seen at lower concentrations of both sugars $(0.1$ and $0.5 \%$, respectively; data not shown). Overall, growth
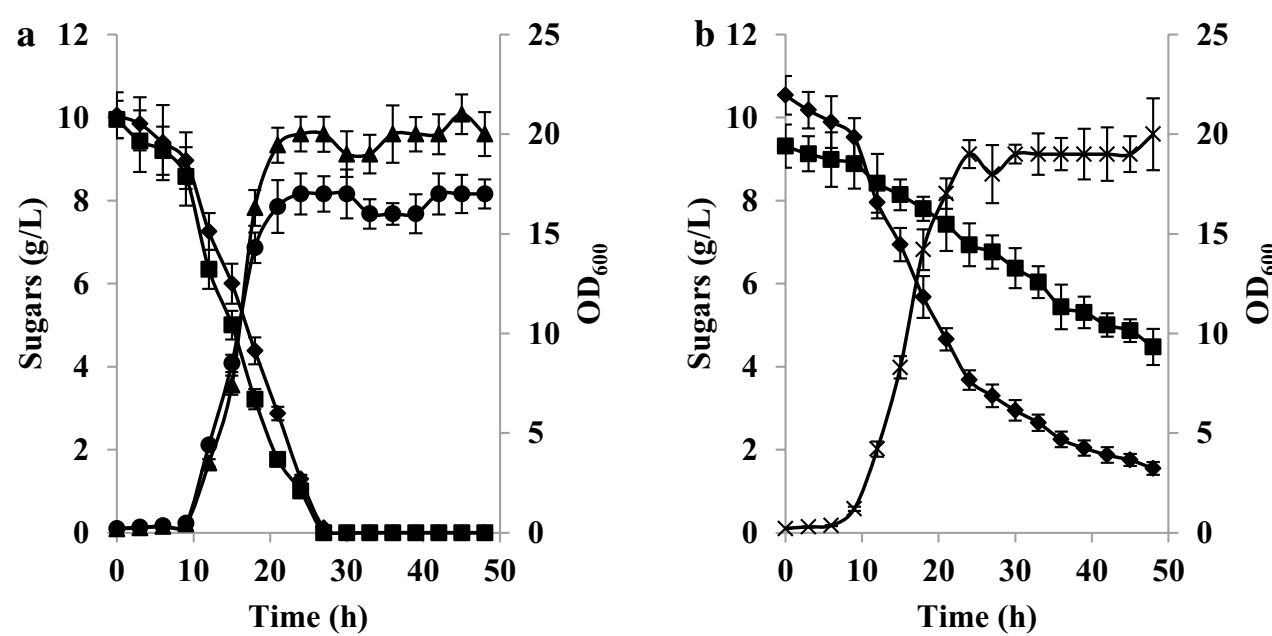

Fig. 7 Yarrowia lipolytica Y4588 growth and sugar consumption over $48 \mathrm{~h}$ in YNB medium containing only $1 \%$ glucose, only $1 \%$ galactose (a), or a mixture of both $1 \%$ glucose and $1 \%$ galactose $(\mathbf{b})$. Glucose (filled diamond), galactose (filled square), $\mathrm{OD}_{600}$ in glucose (filled triangle), $\mathrm{OD}_{600}$ in galactose (filled circle), and $\mathrm{OD}_{600}$ in the mixture of both sugars $(x)$ 
and sugar consumption were the same on the glucoseonly and mixed-sugar media; for instance, at $18 \mathrm{~h}$ of incubation, consumption was around $5.5-6 \mathrm{~g} / \mathrm{L}$ for both (Fig. 7). Even though the galactose utilization pathway had clearly been activated, glucose was obviously the preferred carbon source.

The transport of galactose inside the cell is the first step in the metabolic process. It may be modified in the quadruple mutant or may be affected by the presence of glucose. In Y. lipolytica, six genes have been identified as hexose transporters from a HXT-like family; they have been named in series, YHT1 to YHT6, and have been reported to transport galactose (Lazar et al., in preparation; [26]). The uptake efficiency of both galactose and glucose was compared in S. cerevisiae hxt null mutants transformed with each of these six genes (Additional file 3A). Four of the transporters, YHT1-YHT4, allowed significant galactose or glucose consumption; uptake efficiency, however, varied (Additional file 3A). Only two of the transporters, YHT1 and YHT4, were expressed at high levels in Y. lipolytica Y4588 strain grown in either $1 \%$ glucose or $1 \%$ galactose, similarly as in the W29 (WT) strain (Additional file 3B). These findings suggest that this set of galactose transporters is affected neither by the genetic background (WT or Y4588) nor by the carbon source. Because galactose consumption was much slower in the presence of glucose, it can be hypothesized that galactose transport was somehow inhibited due to competition with glucose, even if their expression was not repressed. However, potential interactions between glucose metabolism and galactose metabolism cannot be excluded.

\section{Galactose is a good substrate for industrial processes using Yarrowia lipolytica}

To confirm that galactose could be effectively used in industrial applications (e.g., the Y. lipolytica Y4588 strain could efficiently produce citric acid and lipids), batch cultures were raised in flasks and bioreactors. All the biomass, citric acid, and lipid production results are summarized in Table 2.

The $Y$. lipolytica wild-type (W29) and quadruple mutant (Y4588) strains produced similar amounts of biomass $(\sim 11 \mathrm{~g} / \mathrm{L})$ when grown in both glucose and galactose media with $\mathrm{C} / \mathrm{N}$ ratio of 60 . Biomass yield ranged from 0.19 to $0.24 \mathrm{~g} / \mathrm{g}$. When the $\mathrm{C} / \mathrm{N}$ ratio of the galactose medium was increased to 100 , biomass yield decreased slightly (11\%).

Interestingly, in glucose, citric acid biosynthesis and yield were around four times higher for Y4588 than for W29. Furthermore, Y4588 was able to produce three times more citric acid from galactose $(\mathrm{C} / \mathrm{N} 60)$ than did W29 grown in glucose. Finally, when the $\mathrm{C} / \mathrm{N}$ ratio was increased to 100 , biomass and citric acid yield from galactose increased by 55 and $37 \%$, respectively.

Galactose could also be used to efficiently produce lipids. In glucose with a C/N ratio of 60, W29 and Y4588 produced similar amounts of total lipids. Y4588 was able to produce comparable amounts of total lipids in galactose- and glucose-only media (Table 2). Lipid yields for W29 and Y4588 ranged between 0.034 and $0.041 \mathrm{~g} / \mathrm{g}$. In addition, increasing the $\mathrm{C} / \mathrm{N}$ ratio to 100 improved the lipid accumulation by $20 \%$; it reached $0.212 \mathrm{~g} / \mathrm{g}$. W29 had similar or lower yields when grown in glucose or fructose media with the same $\mathrm{C} / \mathrm{N}$ ratio [2].

To study Y4588's ability to produce citric acid and lipids in large quantities, the process was scaled up production by using 2-L bioreactors; this approach was informed by previous results obtained for galactose flask cultures (C/N ratio of 100). Overall, biomass, citric acid, and lipid production were dramatically improved (Table 2). Up to $19.4 \mathrm{~g} / \mathrm{L}$ of biomass was produced under these conditions, representing an increase of $100 \%$. Citric acid production reached $29.2 \mathrm{~g} / \mathrm{L}$ and thus the conversion of substrate to citric acid was improved by $31 \%$. In addition, the lipid production increased from 1.79 to $3.22 \mathrm{~g} / \mathrm{L}$,

Table 2 Biomass, citric acid, and lipid production

\begin{tabular}{|c|c|c|c|c|c|c|c|c|c|}
\hline Parameter & & $X(\mathrm{~g} / \mathrm{L})$ & $Y_{\mathrm{X} / \mathrm{s}}(\mathrm{g} / \mathrm{g})$ & $C A(g / L)$ & $Y_{\mathrm{CA} / \mathrm{s}}(\mathrm{g} / \mathrm{g})$ & $Y_{\mathrm{CA} / \mathrm{X}}(\mathrm{g} / \mathrm{g})$ & FA (g/L) & $Y_{\mathrm{FA} / \mathrm{S}}(\mathrm{g} / \mathrm{g})$ & $Y_{\mathrm{FA} / \mathrm{X}}(\mathrm{g} / \mathrm{g})$ \\
\hline \multicolumn{10}{|l|}{ Flasks } \\
\hline \multirow[t]{2}{*}{ Glu 6 \% (C/N 60) } & W29 & 11.15 & 0.24 & 4.18 & 0.09 & 0.37 & 1.92 & 0.041 & 0.172 \\
\hline & Y4588 & 10.90 & 0.21 & 18.17 & 0.35 & 1.67 & 1.87 & 0.036 & 0.172 \\
\hline Gal 6 \% (C/N 60) & & 11.27 & 0.19 & 12.58 & 0.22 & 1.12 & 1.98 & 0.034 & 0.176 \\
\hline Gal $6 \%$ (C/N 100) & & 8.45 & 0.17 & 16.96 & 0.35 & 2.01 & 1.79 & 0.037 & 0.212 \\
\hline \multicolumn{10}{|l|}{ Bioreactors } \\
\hline Gal $6 \%$ (C/N 100) & Y4588 & 19.4 & 0.34 & 29.2 & 0.51 & 1.51 & 3.22 & 0.056 & 0.166 \\
\hline
\end{tabular}

Y. lipolytica W29 and Y4588 strains were grown for $96 \mathrm{~h}$ in YNB medium containing $6 \%$ glucose or $6 \%$ galactose in flasks and bioreactors In this analysis, SD did not exceed $7.5 \%$

$X$ dry biomass, $F A$ fatty acids, $C A$ citric acid, $Y_{X / S}$ yield of biomass from substrate consumed, $Y_{C A / S}$ yield of citric acid from substrate consumed, $Y_{C A / X}$ yield of citric acid from dry biomass, $Y_{F A / S}$ yield of fatty acids from substrate consumed, $Y_{F A / X}$ yield of fatty acids from dry biomass 
which signifies that $34 \%$ more galactose was converted into lipids. The construction of a Y. lipolytica strain that is able to produce citric acid and lipids from galactose is a very important step in bypassing issues related to the use of food-based substrates in industrial applications. In addition, it will be important to activate the Leloir pathway in a strain optimized for lipid accumulation to reach as high titer of biolipids from galactose as recently reported by Qiao et al. from glucose [27]. Activation of the Leloir pathway in a strain described recently by Lazar et al. [2] is currently in progress.

\section{Conclusions}

Galactose is potentially a useful alternative source of carbon for microbiological industrial processes. Our research on the Leloir pathway of galactose utilization in Y. lipolytica has revealed that this yeast is more similar to filamentous fungi such as $H$. jecorina, $A$. nidulans, and $A$. niger than to $S$. cerevisiae and $K$. lactis in terms of its genetic organization and gene regulation. The $y l G A L$ genes are not repressed by glucose and are upregulated by galactose. They encode fully functional proteins. Hexose transporters genes involved in galactose transport are expressed on both, glucose and galactose: however, galactose transport is likely inhibited by substrate competition. In addition, $y l G A L$ genes are not expressed enough in wild-type $Y$. lipolytica to allow growth on galactose. A very efficient galactose-metabolizing $Y$. lipolytica strain was created by fully activating the Leloir pathway, making it possible to use this sugar as a substrate in biotechnological applications. This yeast can be successfully used in citric acid and lipid production; making these processes more effective is currently the focus of intensive research worldwide. The use of galactose as an industrial substrate is especially appealing because it is a component of hemicelluloses and is also found in pectins. Consequently, its metabolism by genetically modified microbes may make it possible to efficiently exploit lignocellulosic biomass for biotechnological purposes, reducing the need to use substrates that are already in demand for food production.

\section{Methods}

\section{Yeast strains and plasmids}

The strains and plasmids used in this study are listed in Additional file 4. All the Y. lipolytica transformants derived from the genetic background of the W29 wildtype strain and of the derivative auxotrophic strain PO1d $\left(\mathrm{Ura}^{-} \mathrm{Leu}^{-}\right)$[28]. Because many strains of various kinds overexpressing $Y$. lipolytica GAL genes were created, only the-quadruple overexpressing strain, Y4588, which overexpressed all four of the $y l G A L$ genes, will be described in detail here. Construction of the other strains is depicted in Fig. 8. Plasmids containing $y l G A L$ genes were constructed using URA3ex and LEU2ex selection markers. Strain Y4573, which overexpressed the Y. lipolytica ylGAL1 gene (YALIOC13090g), was obtained by introducing the overexpression cassette from JME2542 containing the URA3ex selection marker into PO1d.

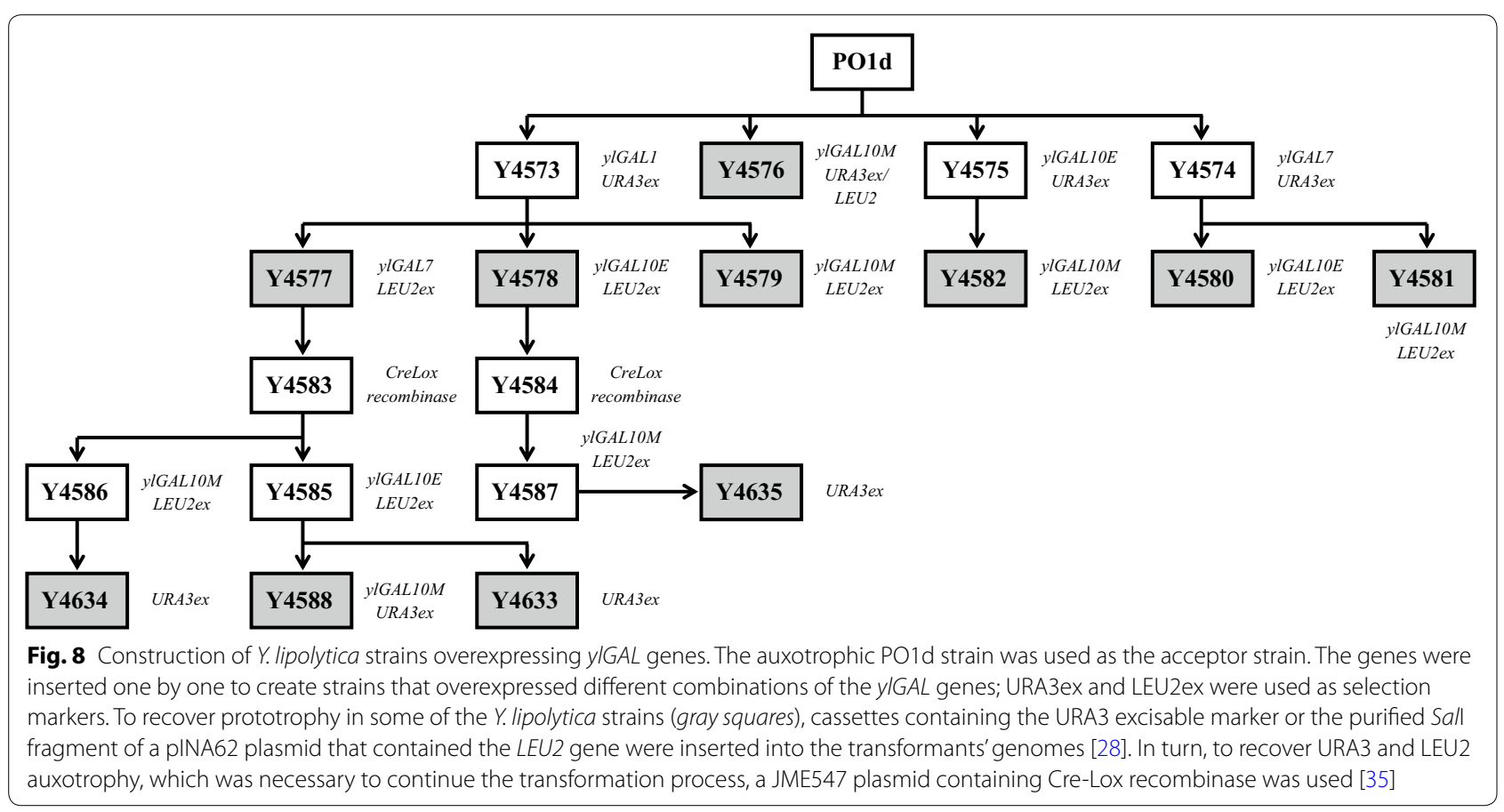


Subsequently, the cassette containing the $y l G A L 7$ gene (YALIOF23947g) and a LEU2ex marker taken from JME2547 was introduced into the Y4573 strain, thus generating the prototrophic Y4577 strain. To excise both selection markers, Y4577 was transformed with JME547 plasmid containing Cre-Lox recombinase and hygromycin selection. This process generated the auxotrophic Y4583 strain $\left(\mathrm{Ura}^{-} \mathrm{Leu}^{-}\right)$. Immediately afterward, the $y$ lGAL1OE gene (YALIOE26829g) overexpression cassette containing the LEU2ex marker from a JME2548 plasmid was introduced into the Y4583. Then, the cassette containing the $y l G A L 10 M$ gene (YALIOC09570g) and the URA3ex marker taken from a JME2545 plasmid was introduced, generating Y4588, which overexpressed the entire Leloir pathway.

The strain Y. lipolytica YLZ68 was obtained by transformation of PO1d strain with NotI digested fragment of ZLE19 vector for $y l G A L 10 E$ gene deletion with URA3ex as selection marker. To recover prototrophy, a purified Sall fragment of the pINA62 plasmid that contained the LEU2 gene was introduced [29].

Yarrowia lipolytica strains expressing S. cerevisiae GAL genes were constructed as depicted in Additional file 5. All the plasmids were prepared as described above.

Functional complementation analysis of the Y. lipolytica GAL genes was performed using S. cerevisiae strains from which the GAL genes had been deleted. The $Y$. lipolytica galactokinase $(y l G A L 1)$ gene was introduced into $S$. cerevisiae $\Delta$ gal1 (Y4475) as well as into the $\Delta$ gal3 (Y4846) strains using JME2735 plasmid, thus generating the Y4595 and Y4875 strains, respectively. To complement the $\triangle$ gal7 strain, a JME2736 plasmid ( $y l G A L 7)$ was introduced into Y4473, generating Y4596. Finally, $\triangle$ gal10 was complemented separately by the $y l G A L 10 E$ and $y l G A L 10 M$ genes, which was accomplished by introducing JME2738 and JME2739 plasmids into the Y4474 strain, yielding Y4597 and Y4690, respectively. All the $S$. cerevisiae deletion mutants-the control strains-were also complemented for uracil auxotrophy by the insertion of an empty pRS426TEF vector.

All the genes introduced into Y. lipolytica and S. cerevisiae were under the control of the constitutive TEF promoter [30]. Yeast transformation was performed using the lithium acetate procedure [31]. Expression cassettes were integrated into the genome of $Y$. lipolytica [32] or were in the replicative pRS426TEF vector in S. cerevisiae [30].

\section{General genetic techniques and plasmid construction}

Standard molecular genetics techniques were used throughout this study [33]. Restriction enzymes were obtained from New England Biolabs (Ipswich, England). Genomic DNA from the transformants was prepared using phenol:chlorophorm extraction method. PCR amplification was performed using an Eppendorf 2720 thermal cycler; both Taq (Promega, Madison, WI) and $\mathrm{Pfu}$ (Stratagene, La Jolla, CA) DNA polymerases were employed. PCR fragments were then purified using a QIAgen Purification Kit (Qiagen, Hilden, Germany), and DNA fragments were recovered from the agarose gels using a QIAquick Gel Extraction Kit (Qiagen, Hilden, Germany). The Staden software package was used for gene sequence analysis [34]. The GAL genes were amplified using the primers listed in Additional file 6 . The restriction sites in the primer sequences enabled the genes to be cloned into JME1128 plasmids that had been digested with BamHI-AvrII, as previously described [35]. Auxotrophies were restored via excision using the Cre-lox recombinase system as described previously [36].

The deletion cassette was typically generated by PCR amplification according to Fickers et al. [36]. First, the promoter $(\mathrm{P})$ and terminator $(\mathrm{T})$ regions were amplified from $Y$. lipolytica W29 genomic DNA as the template and with the gene-specific P1/P2 and T1/T2 oligonucleotides as primer pairs (Additional file 6). Primers P2 and T1 contained an extension to introduce the I-sceI restriction site.

For the $y l G A L 10 E$ gene, primer pairs ylGAl10E-P1/ ylGAL10E-P2 and ylGAL10E-T1/ylGAL10E-T2 were used (Additional file 6). The $\mathrm{P}$ and $\mathrm{T}$ regions were purified and used for the second PCR. The resulting PT fragment was ligated into pCR4Blunt-TOPO. The URA3 marker was then introduced at the $I$-sceI site, yielding the construct ZLE19 containing the $y$ lGAL1OE-PUT cassette.

To complement the S. cerevisiae strains GAL genes of which had been deleted, the corresponding genes were cloned in a pRS426 vector using the constitutive TEF promoter and the uracil selection marker. The corresponding $y l G A L$ genes were amplified and digested, as described above, with the restriction enzymes listed in Additional file 6 .

\section{Growth media}

Media and growth conditions for Escherichia coli were identical to those as described by Sambrook and Russell [33], as were those of Y. lipolytica [28]. Rich (YPD) medium was prepared using $20 \mathrm{~g} / \mathrm{L}$ Bacto $^{\mathrm{TM}}$ Peptone (Difco, Paris, France), $10 \mathrm{~g} / \mathrm{L}$ yeast extract (Difco), and $20 \mathrm{~g} / \mathrm{L}$ glucose (Merck, Fontenay-sous-Bois, France). Minimal (YNB) medium was prepared using $1.7 \mathrm{~g} / \mathrm{L}$ yeast nitrogen base (without amino acids and ammonium sulfate, Difco), $10 \mathrm{~g} / \mathrm{L}$ glucose (Merck), $5 \mathrm{~g} / \mathrm{L} \mathrm{NH}_{4} \mathrm{Cl}$, and $50 \mathrm{mM}$ phosphate buffer ( $\mathrm{pH}$ 6.8). To complement the auxotrophies, $0.1 \mathrm{~g} / \mathrm{L}$ uracil or leucine (Difco, Paris, France) was added as necessary. 


\section{Growth in microtiter plates}

Precultures were obtained from frozen stock, inoculated into tubes containing $5 \mathrm{~mL}$ YPD medium, and cultured overnight $\left(170 \mathrm{rpm}, 28{ }^{\circ} \mathrm{C}\right)$. They were then washed with sterile distilled water; cell suspensions were adjusted to an $\mathrm{OD}_{600}$ of 0.1. Yeast strains were grown in 96-well plates in $200 \mu \mathrm{L}$ of minimal YNB medium containing $10 \mathrm{~g} / \mathrm{L}$ of either glucose or galactose. Culturing was repeated three times; $2-3$ technical replicates were performed for each condition. Cultures were maintained at $28{ }^{\circ} \mathrm{C}$ under constant agitation using a Biotek Synergy MX microtiter plate reader (Biotek Instruments, Colmar, France); each culture's optical density at $600 \mathrm{~nm}$ was measured every $20 \mathrm{~min}$ for $72 \mathrm{~h}$.

\section{Growth and media used in the experiments}

Initial precultures were established by inoculating $50 \mathrm{~mL}$ of YPD medium in 250-mL Erlenmeyer flasks with the yeast strains; this was followed by an overnight shaking step at $28{ }^{\circ} \mathrm{C}$ and $170 \mathrm{rpm}$. The cell suspensions were washed three times with sterile distilled water and used to inoculate $50 \mathrm{~mL}$ of $\mathrm{YNB}$ medium to an $\mathrm{OD}_{600}$ of 0.25 . The cultures were grown until all the available sugar had been consumed.

In the galactose utilization experiment, the YNB medium contained one of the following: $1.0 \mathrm{~g} / \mathrm{L}$ of glucose; $1.0 \mathrm{~g} / \mathrm{L}$ of galactose; $1.0 \mathrm{~g} / \mathrm{L}$ of both glucose and galactose; or $10.0 \mathrm{~g} / \mathrm{L}$ of both glucose and galactose. In addition, galactose utilization was observed in YNB medium containing $10.0 \mathrm{~g} / \mathrm{L}$ of galactose and either 1.0; $2.0 ; 4.0 ; 6.0 ; 8.0$; or $10.0 \mathrm{~g} / \mathrm{L}$ of glucose.

\section{Analysis of growth on galactose by drop test}

To analyze the different strains' growth on galactose, a drop test was performed on cultures grown on YNB plates. The $Y$. lipolytica strains were grown in $5 \mathrm{~mL}$ of YPD medium for $24 \mathrm{~h}$. The cell suspensions were then washed twice with water and re-suspended at an $\mathrm{OD}_{600}$ of 1 . Successive tenfold dilutions were performed $\left(10^{0}-\right.$ $10^{-5}$ ), and $5 \mu$ lof each dilution were spotted onto YNB plates containing $10.0 \mathrm{~g} / \mathrm{L}$ of glucose, $1.0 \mathrm{~g} / \mathrm{L}$ of galactose, or $10.0 \mathrm{~g} / \mathrm{L}$ of galactose. Pictures were taken after the cultures had been incubated at $28^{\circ} \mathrm{C}$ for $48 \mathrm{~h}$. The same protocol was used for the S. cerevisiae strains. However, the YNB media on which they were grown contained the following: $10.0 \mathrm{~g} / \mathrm{L}$ of either glucose or galactose; $6.5 \mathrm{~g} / \mathrm{L}$ of $\mathrm{YNB} ; 10.0 \mathrm{~g} / \mathrm{L}$ of $\left(\mathrm{NH}_{4}\right)_{2} \mathrm{SO}_{4} ; 0.018 \mathrm{~g} / \mathrm{L}$ of leucin; $0.0115 \mathrm{~g} / \mathrm{L}$ of histidin; and $0.025 \mathrm{~g} / \mathrm{L}$ of lysin.

\section{Analysis of galactose uptake by Yarrowia lipolytica hexose transporters}

To analyze galactose uptake, $Y$. lipolytica hexose transporters were expressed one at a time in the S. cerevisiae hxt null mutant strain EBY.VW4000 (kindly provided by E. Boles, Goethe University, Frankfurt am Main, Germany) using a replicative pRS426 vector containing the TEF promoter [Lazar et al., in preparation]. The cells were grown in $5 \mathrm{~mL}$ of YNB medium containing $20 \mathrm{~g} / \mathrm{L}$ of maltose; the medium was refreshed 3 times per 24-h period to increase $2 \mu$ plasmid copy number. The cell suspensions were washed three times with sterile distilled water and used to inoculate $50 \mathrm{~mL}$ of YNB medium that contained either $10.0 \mathrm{~g} / \mathrm{L}$ of glucose or $10.0 \mathrm{~g} / \mathrm{L}$ of galactose. The culture conditions were as described above ("Growth and media used in the experiments"). $\mathrm{OD}_{600}$ and sugar concentration were analyzed.

\section{Conditions and media used for lipid biosynthesis from galactose in flasks and bioreactors}

The precultures were prepared as described above ("Growth and media used in the experiments"). The main culture was grown on $50 \mathrm{~mL}$ of YNB medium (C/N 60) containing the following: galactose $60.0 \mathrm{~g}$; YNB $1.7 \mathrm{~g}$; $\mathrm{NH}_{4} \mathrm{Cl} 1.5$ g; $0.7 \mathrm{~g} \mathrm{KH}_{2} \mathrm{PO}_{4}$, and $1.0 \mathrm{~g} \mathrm{MgSO}_{4} \times 7 \mathrm{H}_{2} \mathrm{O}$ in $1 \mathrm{~L}$. The $\mathrm{pH}$ was kept at 6.8 using $0.05 \mathrm{M}$ phosphate buffer. Tap water was used as a source of microelements. To increase the $\mathrm{C} / \mathrm{N}$ ratio of the medium to $100,1.25 \mathrm{~g} / \mathrm{L}$ of $\mathrm{NH}_{4} \mathrm{Cl}$ was used. Culture conditions were as described above ("Growth and media used in the experiments").

Lipid biosynthesis was also evaluated using batch cultures (BC) that were kept in 5-L stirred-tank BIOSTAT B-PLUS bioreactors (Sartorius, Frankfurt, Germany) for $96 \mathrm{~h}$ under the following conditions: 2-L working volume, $28{ }^{\circ} \mathrm{C}, 800 \mathrm{rpm}$ of agitation, and $3.5-\mathrm{L} / \mathrm{min}$ aeration rate. The production medium was prepared as described above. The $\mathrm{pH}$ was kept at 6.8 using a $40 \%(\mathrm{w} / \mathrm{v}) \mathrm{NaOH}$ solution. The cultures were grown in $0.2 \mathrm{~L}$ of YPD medium in 0.5 - L flasks at $170 \mathrm{rpm}$, at $28{ }^{\circ} \mathrm{C}$ for $48 \mathrm{~h}$. The volume of the inocula added to the bioreactor cultures was equal to $10 \%$ of the total working volume.

\section{Analysis of yIGAL gene and hexose transporter expression}

For the expression experiments, the wild-type strain (W29) and the quadruple mutant (Y4588) were grown at $28{ }^{\circ} \mathrm{C}$ in YNB medium that had been supplemented with $10 \mathrm{~g} / \mathrm{L}$ glucose. After $16 \mathrm{~h}$, the cell suspensions were washed twice with distilled water and transferred into fresh YNB medium with various sugars. For single sugar experiment, the fresh medium contained either 1.0 or $10.0 \mathrm{~g} / \mathrm{L}$ of glucose, galactose, or mannose. Samples were harvested at $3 \mathrm{~h}$ post inoculation; three replicates were obtained. For the kinetics experiments, the cells were transferred to $1.0 \%$ glucose, $1.0 \%$ galactose or mixture of both $1.0 \%$ glucose and $1.0 \%$ galactose. The samples were harvested at 3, 6, 9 and $24 \mathrm{~h}$ 
post inoculation; three replicates were obtained. All the samples were frozen in liquid nitrogen and stored at $-80{ }^{\circ} \mathrm{C}$.

Total RNA was extracted using the RNeasy Mini Kit (Qiagen, Hilden, Germany), and $1.5 \mu \mathrm{g}$ of each sample was treated with DNase (Ambion, Life Technologies). cDNA was synthesized using the Maxima First Strand cDNA Synthesis Kit for RT-qPCR (Thermo Scientific). PCR reactions were performed using specific primers that targeted the $3^{\prime}$ end of the genes (Additional file 6). For the semiquantitative RT-PCR analyses, PCR was performed using the GoTaq DNA Polymerase Kit (Promega). For the quantitative RT-PCR analyses, gDNA dilutions were first tested for primer efficiency and then retained if their efficiency rating was higher than $90 \%$. Amplifications were carried out using the Sso Advanced Universal SYBR Green Supermix Kit (BIO-RAD). The following program was used: $98^{\circ} \mathrm{C}$ for $3 \mathrm{~min}$, followed by 40 cycles of $98^{\circ} \mathrm{C}$ for $15 \mathrm{~s}, 58^{\circ} \mathrm{C}$ for $30 \mathrm{~s}$, and $72{ }^{\circ} \mathrm{C}$ for $30 \mathrm{~s}$. Finally, melting curves were generated to confirm amplification specificity. Both $\Delta C_{\mathrm{T}}$ and $\Delta \Delta C_{\mathrm{T}}$ methods were used to calculate relative expression levels; a constitutive gene, actin, was utilized as the reference control [37].

\section{Analytical techniques used in this study}

Lipid bodies were stained with BodiPy ${ }^{\circledR}$ Lipid Probe (2.5 $\mathrm{mg} / \mathrm{mL}$ in ethanol; Invitrogen). Cell suspension samples $\left(\mathrm{OD}_{600}=5\right)$ were incubated for $10 \mathrm{~min}$ at room temperature. Images were obtained using a Zeiss Axio Imager M2 microscope (Zeiss, Le Pecq, France) equipped with a $100 \times$ objective lens and Zeiss filter sets 45 and 46 for fluorescence microscopy. Axiovision 4.8 software (Zeiss, Le Pecq, France) was used for image acquisition.

The fatty acids were converted into methyl esters, analyzed by gas chromatograph (GC) on a Varian Factor Four vf-23 ms column and quantified using C17:0 (Sigma) as internal standard, as described previously [2]. Citric acid, glucose, fructose, and sucrose were identified and quantified by HPLC (UltiMate 3000, Dionex-Thermo Fisher Scientific, UK) using an Aminex HPX87H column coupled with UV $(210 \mathrm{~nm})$ and RI detectors. The column was eluted with $0.01 \mathrm{~N} \mathrm{H}_{2} \mathrm{SO}_{4}$ at a flow rate of $0.6 \mathrm{~mL}$ / min at room temperature. Compounds were identified and quantified via comparisons to standards. Before undergoing HPLC analysis, the samples were filtered on membranes with a pore size of $0.45 \mu \mathrm{m}$.

To determine dry biomass, cell pellets from the $15-\mathrm{mL}$ culture samples were washed twice with distilled water, filtered on the above membranes, and dried at $105{ }^{\circ} \mathrm{C}$ using a WPS 110S weight dryer (Radwag, Poznań, Poland) until a constant mass was reached.

\section{Additional files}

\author{
Additional file 1: Changes in concentration of glucose $(\boldsymbol{)})$ and galactose \\ ) during cultures of Y. lipolytica W29 (A) and YLZ68 (B) in YNB medium \\ with mixture of $1 \%$ of each sugar.
}

Additional file 2: Overexpression of sCGAL and $y / G A L$ genes in Y. lipolytica. Growth of $Y$. lipolytica transformants containing SCGAL genes (SCGAL1,7,10) on YNB medium containing $1 \%$ galactose $(A)$; yeast were incubated for 1 week at $28{ }^{\circ} \mathrm{C}$. Growth of $Y$. lipolytica transformants overexpressing different combinations of $y / G A L$ genes on YNB medium containing $1 \%$ galactose (B); yeast were incubated for 2 weeks at $28^{\circ} \mathrm{C}$.

Additional file 3: Sugar consumption by S. cerevisiae null mutants expressing Y. lipolytica hexose transporters after $72 \mathrm{~h}$ of growth in YNB medium containing $1 \%$ glucose $(\square)$ or $1 \%$ galactose $(\mathbf{\square})$ (A). Expression profiles of $Y$. lipolytica genes encoding hexose transporters in the W29 and Y4588 strains (B). Yeast were incubated for $3 \mathrm{~h}$ in YNB medium containing $1.0 \%$ glucose or $1.0 \%$ galactose. The amplification of the PCR fragment in the genomic DNA served as a control for the primers' efficiency. Abbreviations: In - inoculum.

Additional file 4: Bacteria and yeast strains used in this study.

Additional file 5: Construction of the Y. lipolytica strains in which the scGAL genes were overexpressed. The auxotrophic PO1d strain was used as the acceptor strain. The genes were inserted one by one to create strains that overexpressed different combination of the SCGAL genes; URA3ex and LEU2ex were used as selection markers. To recover auxotrophies necessary to continuing the transformation process, a JME547 plasmid containing Cre-Lox recombinase was used to transform Y. lipolytica $Y 3683$, thus generating strain $Y 3686$ [35]. In turn, to recover prototrophy in the Y. lipolytica Y3687 strain, a purified Sall fragment of the pINA62 plasmid that contained the LEU2 gene was introduced [28].

Additional file 6: List of primers used in this study.

\section{Abbreviations}

Gal: galactose; Glu: glucose; Man: mannose; $C_{T}$ : threshold cycle; $\mathrm{OD}_{600}$ : optical density $(\lambda=600 \mathrm{~nm}) ; X$ : dry biomass; FA: fatty acids; $C A$ : citric acid; $Y_{\mathrm{X} / \mathrm{S}}$ : yield of biomass from substrate consumed; $Y_{C A / S}$ : yield of citric acid from substrate consumed; $Y_{C A / X}$ : yield of citric acid from dry biomass; $Y_{\text {FA/S }}$ : yield of fatty acids from substrate consumed; $Y_{F A / X}$ : yield of fatty acids from dry biomass.

\section{Authors' contributions}

ZL designed and performed the experiments, analyzed and interpreted the data, wrote, and revised the manuscript; HGM designed and performed real-time PCR experiments, discussed and participated in results interpretation, and revised the manuscript; AMCL participated in hexose transporters experiment, helped in results interpretation, and revised the manuscript; CN performed YALI genome analysis, participated in results analysis and interpretation, and revised the manuscript; JMN participated in designing of the experiments, participated in results analysis and interpretation, as well as revised the manuscript. All authors read and approved the final manuscript.

\section{Author details}

${ }^{1}$ INRA, UMR1319 Micalis, 78352 Jouy-en-Josas, France. ${ }^{2}$ AgroParisTech, UMR Micalis, 78352 Jouy-en-Josas, France. ${ }^{3}$ Department of Biotechnology and Food Microbiology, Wroclaw University of Environmental and Life Sciences, Chełmońskiego 37/41, 51-630 Wroclaw, Poland.

\section{Acknowledgements}

This work was funded by the French National Research Agency (Agence Nationale de la Recherche; Investissements d'avenir program; reference ANR-11-BTBR-0003) and the French National Institute for Agricultural Research (INRA). Z. Lazar received financial support from the European Union in the form of an AgreenSkills Fellowship (Grant Agreement No. 267196; MarieCurie FP7 COFUND People Program). We thank Huu-Vang Nguyen for fruitful 
discussions, Prof. Eckhard Boles for the S. cerevisiae hxt null mutant EBY. VW4000 strain, and Dr. Markus Künzler for the plasmids used to express genes in S. cerevisiae. We would also like to thank Jessica Pearce and Lindsay Higgins for their language editing services.

\section{Competing interests}

The authors declare that they have no competing interests.

Received: 3 July 2015 Accepted: 28 October 2015

Published online: 25 November 2015

\section{References}

1. Beopoulos A, Haddouche R, Kabran P, Dulermo T, Chardot T, Nicaud JM. Identification and characterization of DGA2, an acyltransferase of the DGAT1 acyl-CoA:diacylglycerol acyltransferase family in the oleaginous yeast Yarrowia lipolytica. New insights into the storage lipid metabolism of oleaginous yeasts. Appl Microbiol Biotechnol. 2012;93(4):1523-37.

2. Lazar Z, Dulermo T, Neuvéglise C, Crutz-Le Coq AM, Nicaud JM. Hexokinase- a limiting factor in lipid production from fructose in Yarrowia lipolytica. Met Eng. 2014;26:89-99.

3. Mirończuk AM, Furgała J, Rakicka M, Rymowicz W. Enhanced production of erythritol by Yarrowia lipolytica on glycerol in repeated batch cultures. $J$ Ind Microbiol Biotechnol. 2014;41(1):57-64.

4. Blazeck J, Hill A, Liu L, Knight R, Miller J, Pan A, Otoupal P, Alper HS. Harnessing Yarrowia lipolytica lipogenesis to create a platform for lipid and biofuel production. Nat Comm. 2014;5:3131.

5. Christensen U, Gruben BS, Madrid S, Mulder H, Nikolaev I, de Vries RP. Unique regulatory mechanism for D-galactose utilization in Aspergillus nidulans. Appl Environ Microbiol. 2011;77(19):7084-7.

6. Wong TY, Yao XT. The DeLey-Doudoroff pathway of galactose metabolism in Azotobacter vinelandii. Appl Environ Microbiol. 1994;60(6):2065-8.

7. Mojzita D, Herold S, Metz B, Seiboth B, Richard P. L-Xylo-3-hexulose reductase is the missing link in the oxidoreductive pathway for $\mathrm{D}$-galactose catabolism in filamentous fungi. J Biol Chem. 2012;287(31):26010-8.

8. Meyer J, Walker-Jonah A, Hollenberg CP. Galactokinase encoded by GAL1 is a bifunctional protein required for the induction of the GAL genes in Kluyveromyces lactis and is able to suppress the gal3 phenotype of Saccharomyces cerevisiae. Mol Cell Biol. 1991;11:5454-61.

9. Sellick CA, Campbell RN, Reece RJ. Galactose metabolism in yeaststructure and regulation of the Leloir pathway enzymes and the genes encoding them. Int Rev Cell Mol Biol. 2008;269:111-50.

10. Slot JC, Rokas A. Multiple GAL pathway gene clusters evolved independently and by different mechanisms in fungi. PNAS. 2010;107(22):10136-41.

11. Bouffard GG, Rudd KE, Adhya SL. Dependence of lactose metabolism upon mutarotase encoded in the gal operon in Escherichia coli. J Mol Biol. 1994;162:156-9

12. Zaman S, Lippman SI, Zhao X, Broach JR. How Saccharomyces responds to nutrients. Annu Rev Genet. 2008:42:27-81.

13. Gancedo JM. Yeast carbon catabolite repression. Microbiol Mol Biol Rev. 1998;62(2):334-61.

14. Horak J, Wolf DH. Catabolite inactivation of the galactose transporter in the yeast Saccharomyces cerevisiae: ubiquitination, endocytosis, and degradation in the vacuole. J Bacteriol. 1997;179:1541-9.

15. Cardinali G, Vollenbroich V, Jeon MS, de Graaf AA, Hollenberg CP. Constitutive expression in gal7 mutants of Kluyveromyces lactis is due to the internal production of galactose as an inducer of the Gal/Lac regulon. Mol Cell Biol. 1997;17(3):1722-30.

16. Hartl L, Kubicek CP, Seiboth B. Induction of the gal pathway and cellulase genes involves no transcriptional inducer function of the galactokinase in Hypocrea jecorina. J Biol Chem. 2007;282(25):18654-9.

17. Seiboth B, Hofmann G, Kubicek CP. Lactose metabolism and cellulase production in Hypocrea jecorina: the gal7 gene, encoding galactose1-phosphate uridylyl-transferase, is essential for growth on galactose but not for cellulase induction. Mol Genet Genomics. 2002;267:124-32.
18. Seiboth B, Karaffa L, Sandor E, Kubicek C. The Hypocrea jecorina gal10 (uridine 5'-diphosphate-glucose 4-epimerase) encoding gene differs from yeast homologues in structure, genomic organization and expression. Gene. 2002;295:143-9.

19. Seiboth B, Harti L, Pali M, Fekete E, Karaffa L, Kubicek C. The galactokinase of Hypocrea jecorina is essential for cellulase induction by lactose but dispensable for growth on D-galactose. Mol Microbiol. 2004;51(4):1015-25.

20. Fekete E, de Vries RP, Seiboth B, vanKuyk PA, Sándor E, Fekete E, Metz B, Kubicek CP, Karaffa L. D-Galactose uptake is nonfunctional in the conidiospores of Aspergillus niger. FEMS Microbiol Lett. 2012;329(2):198-203.

21. Alam K, Kaminskyj GW. Aspergillus galactose metabolism is more complex than that of Saccharomyces: the story of GalD ${ }^{\mathrm{GAL} 7}$ and GALE ${ }^{\mathrm{GAL}}$. Botany. 2013;91:467-77.

22. Michely S, Gaillardin C, Nicaud JM, Neuvéglise C. Comparative physiology of oleaginous species from the Yarrowia clade. PLoS one. 2013;8(5):e63356 (1-10).

23. Suzuki S, Matsuzawa T, Nukigi Y, Takegawa K, Tanaka N. Characterization of two different types of UDP-glucose/-galactose 4-epimerase involved in galactosylation in fission yeast. Microbiology. 2010;156:708-18.

24. Wang ZP, Xu HM, Wang GY, Chi Z, Chi ZM. Disruption of the MIG1 gene enhances lipid biosynthesis in the oleaginous yeast Yarrowia lipolytica ACA-DC 50109. Biochim Biophys Acta. 2013;1831(4):675-82.

25. van den Brink J, Akeroyd M, van der Hoeven R, Pronk JT, De Winde JH, Daran-Lapujade P. Energetic limits to metabolic flexibility: responses of Saccharomyces cerevisiae to glucose-galactose transition. Microbiology. 2009;155:1340-50.

26. Young E, Poucher A, Comer A, Bailey A, Alper H. Functional survey for heterologous sugar transport proteins, using Saccharomyces cerevisiae as a host. Appl Environ Microbiol. 2011;77(10):3311-9.

27. Qiao K, Abidi SHI, Liu H, Zhang H, Chakraborty S, Watson N, Ajikumar PK, Stephanopoulos G. Engineering lipid overproduction in the oleaginous yeast Yarrowia lipolytica. Met Eng. 2015;29:56-65.

28. Barth G, Gaillardin C. Yarrowia lipolytica. In: Wolf K, Breunig KD, Barth G editors. Nonconventional yeasts in biotechnology, vol. 1. Berlin: SpringerVerlag; 1996. p. 313-88.

29. Gaillardin C, Ribet AM. LEU2 directed expression of $\beta$-galactosidase activity and phleomycin resistance in Yarrowia lipolytica. Curr Genet. 1987;11:369-75.

30. Mumberg D, Müller R, Funk M. Yeast vectors for the controlled expression of heterologous proteins in different genetic backgrounds. Gene. 1995;156:119-22.

31. Xuan JW, Fournier P, Declerck N, Chasles M, Gaillardin C. Overlapping reading frames at the LYS5 locus in the yeast Yarrowia lipolytica. Mol Cell Biol. 1990;10:4795-806.

32. Mauersberger S, Wang HJ, Gaillardin C, Barth G, Nicaud JM. Insertional mutagenesis in the $n$-alkane-assimilating yeast Yarrowia lipolytica: generation of tagged mutations in genes involved in hydrophobic substrate utilization. J Bacteriol. 2001;183:5102-9.

33. Sambrook J, Russell DW. Molecular cloning: a laboratory manual. 3rd ed. New York: Cold Spring Harbor Laboratory Press; 2001.

34. Dear S, Staden R. A sequence assembly and editing program for efficient management of large projects. Nucleic Acids Res. 1991;19(14):3907-11.

35. Dulermo T, Tréton B, Beopoulos A. Kabran Gnankon AP, Haddouche R, Nicaud JM. Characterization of the two intracellular lipases of $Y$. lipolytica encoded by TGL3 and TGL4 genes: new insights into the role of intracellular lipases and lipid body organisation. Biochim Biophys Acta. 2013;1831(9):1486-95.

36. Fickers P, Le Dall MT, Gaillardin C, Thonart P, Nicaud JM. New disruption cassettes for rapid gene disruption and marker rescue in the yeast Yar rowia lipolytica. J Microbiol Meth. 2003;55:727-37.

37. Schmittgen TD, Livak KJ. Analyzing real-time PCR data by the comparative CT method. Nat Protoc. 2008;3(6):1101-8. 